\title{
PERIOSTITIS OF THE METATARSUS.
}

\author{
BY \\ WILFRID ATTLEE, M.D., M.R.C.P., \\ Physician, King Edward VII Hospital, Windsor. \\ Member of Eton College Medical Board.
}

Several descriptions have been published during the last few years of affections of the metatarsus. These affections have been given various names, such as "marching fractures," "acute metatarsal overstrain" and "chronic œdema of the feet." They are alike in that apparently healthy people have been affected without any definite cause, and the descriptions give the impression that in spite of different titles they all apply to one and the same condition in different stages.

It is thought that the following notes of three cases may be of interest, because they record the whole course of the disease from the beginning of the first symptoms to their complete disappearance.

All the patients were schoolboys and the trouble began without any history of injury or other obvious cause, although, of course, life at schnol naturally lends itself to minor injuries at football and other games.

In all three cases the first complaint was of pain in the dorsum of the foot, accompanied by a little swelling and tenderness over the middle of the metatarsal region. At this stage skiagrams showed nothing abnormal but a faint shadow round the middle of the shaft of a metatarsal bone, so faint that it was completely over-looked in one instance at any rate. The shadow became more marked as time went on, and after a month or so films showed a fracture with considerable callus. After another two or three months nothing more than a slight thickening of the bone was visible.

In one case the disease affected two metatarsals one after the other, the second bone being affected while the foot was being rested on account of the first. In the case of this bone at any rate there was no possibility of injury.

\section{Case Records.}

CASE 1. A particularly well made and healthy schoolboy, aged 14, on June 28th, 1921, complained of pain in the left foot. The dorsum of the foot was a little swollen and tender on pressure over the middle of the second metatarsal. An X-ray film showed a sheath of periosteal new bone round the middle of the shaft of the second metatarsal, without any rarefaction or expansion of the shaft. He was seen by Mr. Harold Wilson, who put the foot in plaster, and he returned to ordinary school life in the following September. He has had no symptoms since in spite of playing hard at all games, and a film in June, 1926, showed a perfectly normal foot.

CASE 2. A schoolboy, aged 15, apparently perfectly healthy, on November 28th, 1925, complained of pain in the right foot. There was slight swelling and tenderness as in case 1 . A skiagram showed a faint shadow round the shaft of the second metatarsal (Fig. 1). On December $27 \mathrm{th}$, the appearance was that of a fracture with considerable callus (Fig. 2). The appearance on February 10th, after resting the foot is shown in Fig. 3. Since then the boy has lived an ordinary life and has had no recurrence. 
METATARSAL PERIOSTITIS.

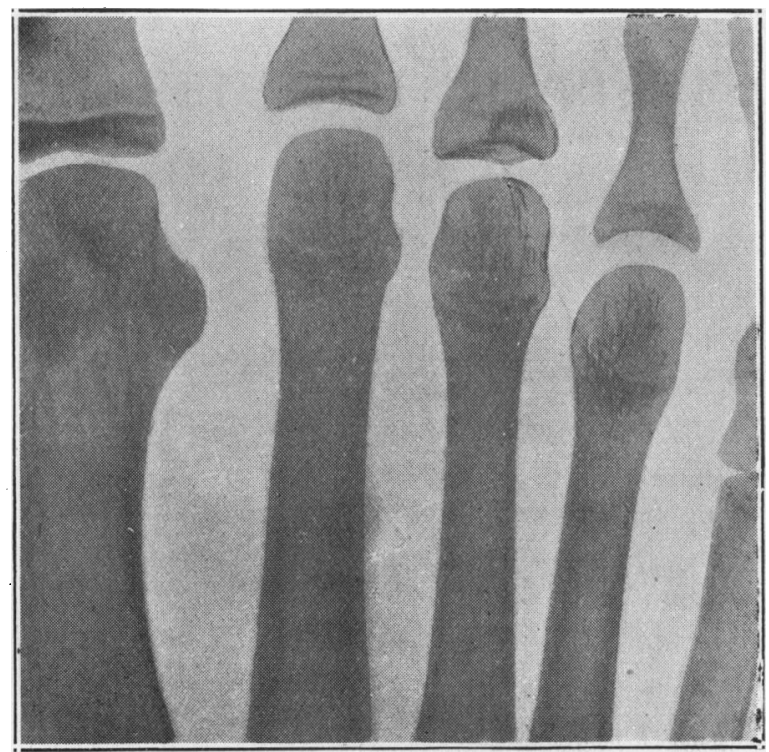

Fig. 1.-Case II., (1/12/25); showing a faint shadow round the shaft of the second metatarsal bone.

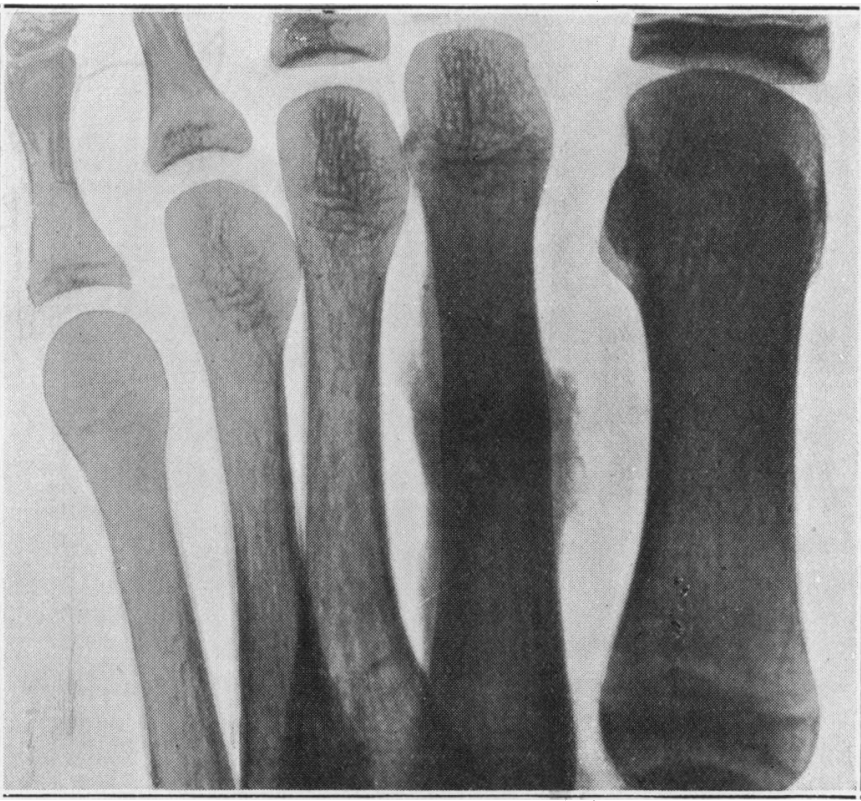

Jig. 2. -. Case II. $(27 / 12 / 25)$; showing a fracture, with considerable callus, of the second metatarsal bone, 
Fig. 4.-Case III., $(29 / 3 / 26)$; showing a faint shadow round the middle of the shaft of the third metatarsal bone. 


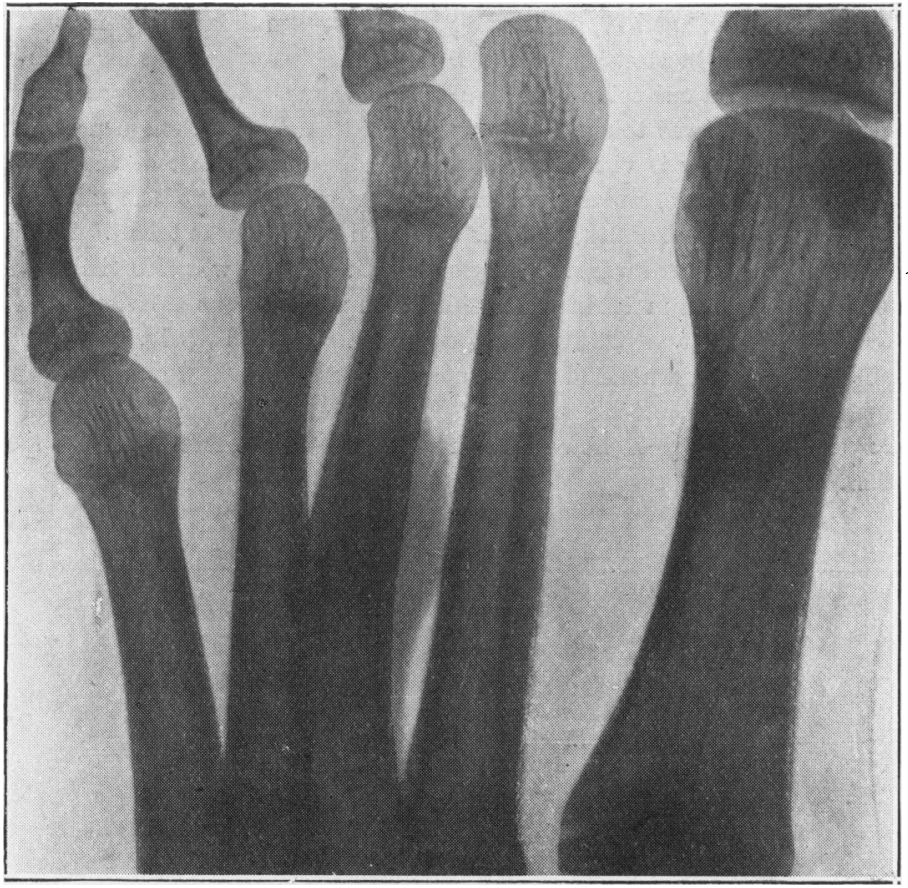

Fig. 6.-Case III., $(21 / 6 / 26)$; showing diminution in the callus round the shaft of the third metatarsal, and thickening round the neck of the fourth metatarsal bone.

Fig. 5.-Case III., $(9 / 5 / 26)$; showing further change in the shaft of the third metatarsal, and a faint shadow round the neck of the fourth metatarsal bone.

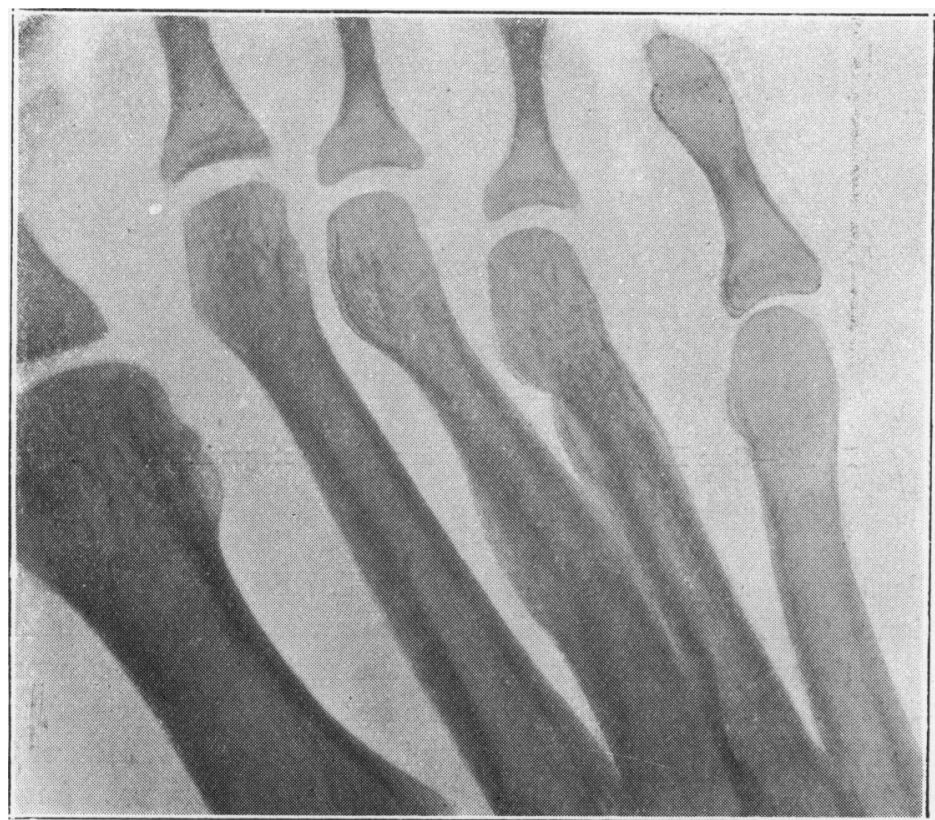


CASE 3. A schoolboy, aged 17, on March 29th, 1926, complained of pain in the right foot. He was very fat (weight, 14 stones; height, $6 \mathrm{ft}$.), and his appearance and late development at one time had aroused a suspicion of Fröhlich's syndrome. With the previous two cases in mind, a skiagram (Fig. 4) was taken. This was passed as normal though now, in the light of after events, a faint shadow is visible round the middle of the shaft of the third metatarsal. He went home for the holidays, and danced and played games in spite of the pain which persisted. On his return to school on May 9th, another skiagram (Fig. 5) was taken. The alteration in the shaft of the third metatarsal was now very obvious, and there was also visible a faint shadow round the neck of the fourth metatarsal, though no importance was attached to it at the time. The foot was rested. At a thi d examination on June 21st, (Fig. 6), there was seen a definite thickening round the neck of the fourth metatarsal, while the callus round the third had become smaller and spindle-shaped. Fig. VII, taken on September 3rd, shows a further stage of recovery. The boy is now-December, 1926-quite free from symptoms and is developing well.

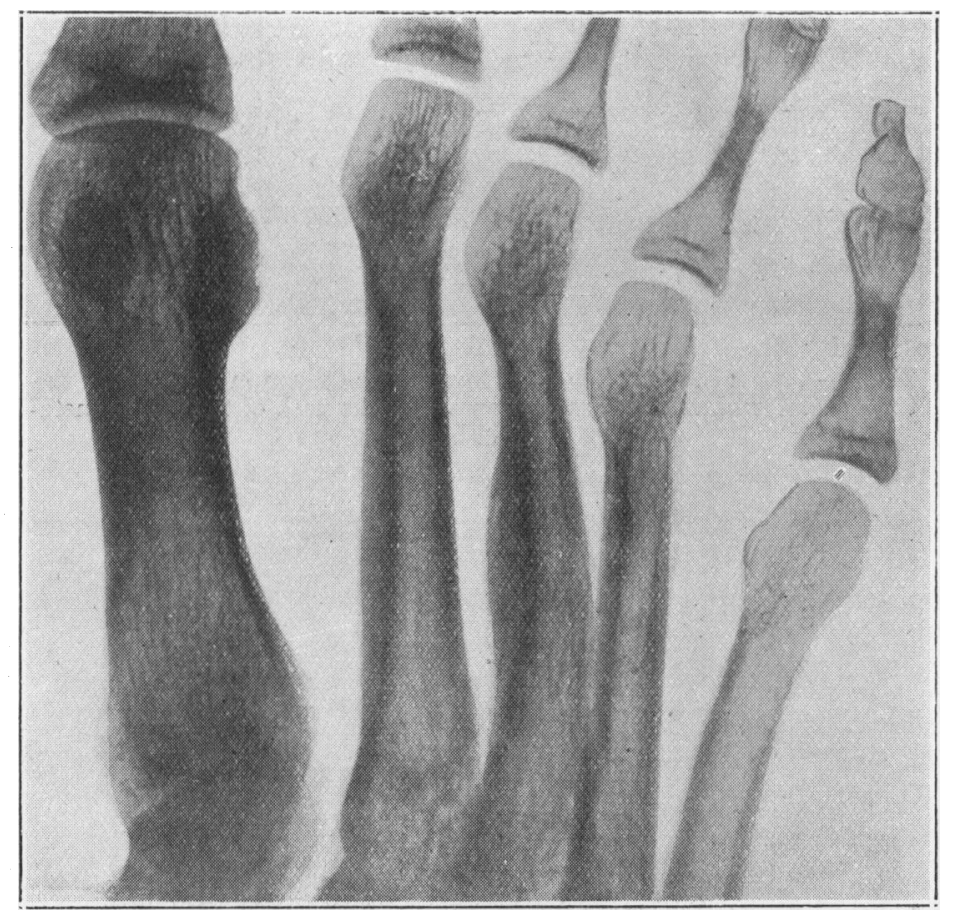

Fig. 7.--Case III., (3/9/27); showing further stages in recovery.

\section{Discussion.}

The last two cases were seen by Mr. H. A. T. Fairbank, and were treated in conjunction with him. He was quite sure from the clinical condition and the films that there was a definite fracture of the metatarsal in both patients.

But it is difficult to be sure whether the fracture was the primary condition or whether there was not some preliminary inflammation. Whatever the cause of the condition may be it seems clear that the old hypotheses of mechanical strain, such as marching with a heavy pack, will not altogether account for the 
sequence of events. All the patients with the exception of the last, were ordinary healthy schoolboys without any marked valgus or other foot affections. Case II had no valgus at all. Case III had slight flattening of the affected foot, but the arch of the other was unusually high. They were all living and playing games as others in the school. The middle of the shaft of the bone, too, was affected and not the neck, where, as A. H. Pirie in his paper on this subject points out, these bones have to bear the greatest breaking strain. There must be some underlying condition which predisposes to the initial periostitis.

The idea of a periostitis after a hæmogenic infection, such as is suggested by Gosta Runstrom, has little to recommend it in these healthy boys, at any rate less than the other suggestion of a nutritional disorder accompanied by a decreased elasticity of the bones.

In Case III noted above, there was certainly some nutritional disturbance causing the adiposity and late development, and some of the X-Ray films show a definite thinning of the bones in this patient.

\section{Conclusions.}

1. There is an affection of the metatarsal bones which can arise in apparently healthy boys of school age without any definite injury.

2. It is a condition which may be easily overlooked, even with an X-ray film, in its early stage.

3. If untreated it can progress until a more or less spontaneous fracture occurs.

4. It begins as a periostitis, and the bone affection, rarefaction and fracture are secondary occurrences.

5. No satisfactory explanation of the cause of the initial periostitis has yet been given.

\section{REFERENCES.}

Deutschländer, C., Zentralb. f. Chir., Leipzig, 1921, XLVIII, ii, 1422.

Havinga, L., Ibid., 1925, LII, i, 1118.

Jones, A. R., Brit. Med. J., Lond., 1918, i, 451.

Pirie, A. H., Lancet, Lond., 1917, ii, 47.

Runstrom, G., Act. Radiol., Stockholm, 1924, III, 42. 